\title{
GERMINAÇÃO E VIGOR DE SEMENTES DE FEIJÃO-CAUPI EM CONDIÇÕES DE DÉFICIT HÍDRICO
}

Marlei Rosa dos Santos ${ }^{1}$, Naira Gerlene Marques Teixeira ${ }^{2}$, Francisco de Assis Gomes Junior $^{3}$, Tamara Santos Ferreira de Farias ${ }^{4}$, Francisco de Assis pereira Leonardo ${ }^{5}$

\footnotetext{
${ }^{1}$ Docente, Fitotecnia, Universidade Estadual do Piauí (UESPI), Uruçuí, PI. E-mail: marleirs@yahoo.com.br. Rua Almir Benvindo S/N, Bairro Malvinas, Uruçuí-PI.

${ }^{2}$ Graduada, Agronomia, Universidade Estadual do Piauí (UESPI), Uruçuí, PI.

${ }^{3}$ Docente, Engenharia Agrícola, Universidade Estadual do Piauí (UESPI), Uruçuí, PI.

4 Doutoranda, Entomologia e Conservação da Biodiversidade, Universidade Federal da Grande Dourados (UFGD), Dourados, MS.

${ }^{5}$ Docente, Solos e nutrição de plantas, Universidade Estadual do Piauí (UESPI), Uruçuí, PI.
}

Recebido: 14/05/2020; Aceito: 10/12/2020

RESUMO: O Brasil encontra-se entre os maiores produtores de feijão-caupi, sendo a região Nordeste a maior produtora no país. No início do ciclo, a água é um fator essencial para o desenvolvimento do embrião e da planta, sendo que sua escassez vem reduzindo drasticamente o estande de plantas e, consequentemente, a produtividade do feijão-caupi. $\mathrm{O}$ experimento foi conduzido com o objetivo de avaliar a germinação e o vigor de sementes de quatro cultivares de feijão-caupi em condições de déficit hídrico. $O$ delineamento experimental utilizado foi inteiramente casualizado, com quatro repetições, no esquema fatorial $4 \times 3$, sendo 4 cultivares (Aracé, Guariba, Gurgueia e Jaquinha) e três potenciais hídricos (85, 70 e 55\% da capacidade de retenção de água). Inicialmente foi determinada a porcentagem de umidade das sementes, a massa de mil sementes, primeira contagem da germinação (vigor) e germinação total. Em diferentes potenciais hídricos e utilizando a areia como substrato, avaliou-se o índice de velocidade de emergência (IVE) e a porcentagem de plântulas normais. O déficit hídrico afetou a velocidade de germinação das sementes de feijão-caupi, porém não influenciou na porcentagem de plântulas emergidas em areia, avaliadas aos 15 dias após a semeadura. A cultivar Gurgueia apresentou maior vigor na primeira contagem de germinação e maior velocidade de germinação e porcentagem de plântulas emergidas após 15 dias da semeadura, independente do potencial hídrico.

Palavras-chave: Vigna unguiculata. Potencial hídrico. Cultivar.

\section{GERMINATION AND VIGOR CAUPI BEAN SEEDS IN WATER DEFICIT CONDITIONS}

\begin{abstract}
Brazil ranks among the largest caupi bean producers, with the northeastern region being the largest producer in the country. Despite being the largest national producer, this region lacks water, which is an essential factor at the initial embryo and plant germination. Thus, water scarcity has drastically reduced the caupi bean plant stand and, consequently, its yield. This experiment was carried out to evaluate the germination and initial growth of the plantlets of four caupi bean cultivars under water deficit conditions. The
\end{abstract}


experiment was carried out in a completely randomized design with four repetitions, in the factorial scheme 4 x 3, using 4 cultivars (Aracé, Guariba, Gurgueia, and Jaquinha), and three water potentials $(85,70$ and $55 \%$ of the water capacity retention). Seed humidity percentage, weight of a thousand seeds, first germination count (vigor) and total germination were initially determined. At different water potentials in the sand, the emergence velocity index (EVI) and normal plant percentage were evaluated. The water deficit affected the speed of germination of cowpea seeds, but did not influence the percentage of seedlings emerged in sand evaluated at 15 days after sowing. The cultivar Gurgueia showed greater vigor in the first germination count and higher germination speed and percentage of seedlings emerged after 15 days of sowing, regardless of water potential.

Keywords: Vigna unguiculata. Water potential. Cultivar.

\section{INTRODUÇÃO}

O feijão-caupi (Vigna unguiculata (L.) Walp) espécie pertencente à família Fabaceae, é uma cultura tradicionalmente explorada por pequenos agricultores, normalmente descapitalizados, e por isso, na maioria das vezes, com emprego de pouca tecnologia (YOKOYAMA, 2002). Essa cultura é fonte de emprego e renda, possui potencial nutricional com alto teor proteico, energético, fibras alimentares e minerais (FROTA et al., 2008). Também conhecido como feijão-de-corda ou feijão-macassar é uma excelente fonte de proteínas (23-25\% em média) e apresentam todos os aminoácidos essenciais, carboidratos (62\%, em média), vitaminas e minerais, além de possuir grande quantidade de fibras dietéticas e baixa quantidade de gordura (teor de óleo de $2 \%$, em média) (ROCHA et al., 2017). Assim, representa alimento básico para as populações de baixa renda do Nordeste brasileiro. Porém, nas regiões Centro-Oeste, Norte e Nordeste tem-se expandido o plantio do feijão-caupi em grandes áreas, como cultura principal ou safrinha, especialmente no cerrado piauiense, onde se observa aumento significativo da área plantada (BEZERRA et al., 2012).

No Brasil, o feijão é cultivado por pequenos, médios e grandes agricultores, com produção anual total de 3.116,2 mil toneladas sendo dessas 790 mil toneladas do feijão-caupi (CONAB, 2019). Seu cultivo é predominantemente no sertão semiárido da região Nordeste e em pequenas áreas na Amazônia, representando 83\% da área total plantada no Brasil. No Nordeste, a produção e a produtividade são de 465,9 mil t e $394 \mathrm{Kg} \mathrm{ha}^{-1}$, respectivamente. Os Estados com maior produção são Mato Grosso (237,3 mil t), Ceará (115,7 mil t), Bahia (100,1 mil t), Piauí (95,5 mil t) e Maranhão (58,2 mil t), os quais também apresentam as maiores áreas plantadas (CONAB, 2019).

No Estado do Piauí o cultivo de feijão-caupi em grande escala está restrito a plantios na safrinha, ou seja, após colheita de milho e soja. Nesta época, as chuvas são escassas e variam a cada ano. Considerando a importância do feijão-caupi para a população de baixa renda e a necessidade de elucidar componentes do comportamento de cultivares desenvolvidas para o plantio em regime de sequeiro na região Nordeste frente às limitações hídricas impostas nessa época, tornam-se necessários trabalhos que visam estudar o efeito do déficit hídrico na germinação e desenvolvimento inicial de cultivares. 
Cultivado predominantemente em climas quentes de regiões semiáridas e subtropicais do mundo (ARAÚJO et al., 2018). O feijão-caupi exige no mínimo $300 \mathrm{~mm}$ de precipitação de água para produção, sem a necessidade de utilização de práticas de irrigação. Assim, as regiões cujas precipitações oscilem entre 250 e $500 \mathrm{~mm}$ são consideradas aptas para a exploração da cultura (ANDRADE JÚNIOR et al., 2002). Na região Meio-Norte do Brasil, a principal causa da variação da produtividade do feijão-caupi em condições de sequeiro está associada à disponibilidade hídrica no solo, devido principalmente à má distribuição das chuvas, que limita o crescimento e o desenvolvimento da cultura (CARDOSO et al., 2000).

As respostas das plantas às condições de estresse hídrico variam de acordo com a espécie, cultivo, tempo de exposição e fatores edáficos, entre outros. Não existe uma única variável fisiológica que, por si só, seja indicativa de tolerância à seca (CARDOSO et al., 2000). É uma cultura pouco exigente no que diz respeito à fertilidade do solo, pois as plantas têm a grande vantagem de absorver e fixar nitrogênio da atmosfera, sendo este um dos elementos essenciais à cultura (SILVA et al., 2010).

O déficit hídrico tem efeito em diversos processos fisiológicos das plantas e já foi objeto de pesquisas realizadas por Endres et al. (2010), Mendes et al. (2007) e Oliveira et al. (2005). Além disso, é um dos fatores que mais compromete a germinação das sementes e o desenvolvimento inicial das plantas, sendo a água responsável pela reativação do metabolismo das sementes e assim, está envolvida direta e indiretamente em todas as demais etapas da germinação (MARCOS FILHO, 2015).

Mesmo sendo uma cultura tolerante a seca, o déficit hídrico aplicado de forma contínua afeta diretamente a germinação, crescimento inicial e vigor de plântulas do feijão-caupi. Objetivou-se com o experimento, avaliar a germinação e o vigor de sementes de quatro cultivares de feijão-caupi em condições de déficit hídrico.

\section{MATERIAL E MÉTODOS}

O experimento foi conduzido no Laboratório de Análise de Sementes da Universidade Estadual do Piauí - UESPI, Campus Cerrado do Alto Parnaíba.

As determinações de teor de umidade e germinação das sementes foram conduzidas no delineamento inteiramente casualizado, com quatro repetições e quatro tratamentos (cultivares). $\mathrm{O}$ teste de emergência em areia foi conduzido no delineamento inteiramente casualizado, com quatro repetições, no esquema fatorial $4 \times 3$, sendo sementes de quatro cultivares de feijão-caupi (Aracé, Guariba, Gurguéia e Jaquinha) e três potenciais hídricos (55, 70 e $85 \%$ da capacidade de retenção de água). As sementes foram doadas pela EMBRAPA Meio Norte e armazenadas em geladeira por 30 dias até o início do trabalho.

Antes da semeadura foi determinado, o teor de umidade, o peso de mil sementes e a porcentagem de germinação das sementes das quatro cultivares de feijão-caupi. O teor de umidade das sementes de cada cultivar foi obtido pelo método de estufa a $105 \pm 3{ }^{\circ} \mathrm{C}$ por 24 horas, seguindo metodologia das Regras de Análise de Sementes - RAS (BRASIL, 2009). A porcentagem de umidade foi calculada com base no peso úmido. O peso de mil sementes foi determinado utilizando oito subamostras de 100 sementes, que foram pesadas em balança 
analítica digital com sensibilidade de 0,001 g, conforme as RAS (BRASIL, 2009). O resultado expresso em gramas por mil sementes.

Para avaliar a germinação, utilizou-se quatro repetições de 50 sementes que foram distribuídas em rolos de papel germitest, umedecido com água na proporção de 2,5 vezes o peso do papel seco. As avaliações foram realizadas aos cinco e oito dias após a instalação do teste, segundo os critérios estabelecidos pela RAS (BRASIL, 2009). Os dados foram expressos em porcentagem de plântulas normais, sendo as porcentagens obtidas na primeira contagem referente ao vigor das sementes e a soma das duas avaliações a germinação total.

Foi determinada a capacidade de retenção de água para a distribuição exata quantidade de água em cada potencial hídrico avaliado. Para o estudo, pesou-se $500 \mathrm{~g}$ de areia seca, colocou-se em um filtro de papel e adicionou-se $500 \mathrm{~mL}$ de água. Subtraindo o volume de água filtrada do volume colocado obteve-se a capacidade de retenção de água da areia. Calculou-se o volume de água correspondente a cada porcentagem de retenção $(55,70$ e 85\%). As sementes foram doadas pela EMBRAPA Meio Norte e armazenadas em geladeira por 30 dias até o início do trabalho.

Para o estudo da emergência das plântulas foram utilizadas quatro repetições de 30 sementes por cultivar em cada potencial hídrico. As sementes foram semeadas a $1,5 \mathrm{~cm}$ de profundidade em bandejas plásticas não perfuradas contendo apenas areia e água de acordo com o tratamento (potencial hídrico). Foram semeadas dez sementes por sulco. A irrigação foi realizada diariamente para manter o potencial hídrico da areia, utilizou-se balança de precisão para manter o peso inicial, de acordo com o tratamento. Após 15 dias da semeadura avaliou-se a porcentagem de plântulas normais. Diariamente as bandejas foram colocadas sobre a balança e adicionou-se água até atingir o peso inicial de cada bandeja.

$O$ índice de velocidade de emergência (IVE) foi avaliado em conjunto com a emergência de plântulas, anotando-se diariamente a porcentagem de plântulas emergidas. Foram consideradas emergidas as plântulas que apresentaram o hipocótilo acima da superfície do solo, ereto e com as folhas cotiledonares completamente abertas. No final do teste calculou-se o IVE, empregando-se a fórmula proposta por Maguire (1962), com modificações.

Os dados obtidos foram submetidos à análise de variância, quando necessário, realizouse a comparação das médias de cultivares e níveis de déficit hídrico pelo teste de Tukey a 5\% de probabilidade, utilizando-se o software ASSISTAT 7.7 (SILVA, 2013).

\section{RESULTADOS E DISCUSSÃO}

Para o teor de umidade inicial das sementes observou-se diferença entre as cultivares. As sementes das cultivares Aracé e Guariba apresentaram menor teor de umidade em comparação às sementes das cultivares Gurgueia e Jaquinha (Tabela 1). As duas primeiras cultivares apresentaram teor de umidade inferior a $13 \%$, valor este considerado adequado para o feijão-caupi (CARDOSO et al., 2017). 
As sementes utilizadas apresentaram os seguintes pesos de mil sementes: Aracé $(308,0$ g), Guariba (208,2 g), Gurgueia (209,2 g) e Jaquinha (105,1g). A diferença de tamanho entre as sementes tem influência na superfície de contato com a água, sendo assim, sementes menores apresentam maior absorção de água, necessitando de menor quantidade de água no solo ou substrato para germinar. Segundo Krzyzanowski et al. (1999) as sementes menores precisam de quantidade menor de água e por isso são as primeiras a germinarem.

Tabela 1. Teor de umidade das sementes, porcentagem de plântulas normais na primeira contagem da germinação (PC) e germinação de sementes de quatro cultivares de feijão-caupi. Seed moisture content, percentage of normal seedlings in the first germination count $(C P)$ and seed germination of four cowpea cultivars.

\begin{tabular}{lccc}
\hline Cultivares & Umidade (\%) & PC (\%) & Germinação (\%) \\
\hline Aracé & $12,76 \mathrm{~b}$ & $64,50 \mathrm{ab}$ & 66,50 \\
Guariba & $12,08 \mathrm{~b}$ & $60,50 \mathrm{~b}$ & 66,00 \\
Gurgueia & $13,80 \mathrm{a}$ & $81,25 \mathrm{a}$ & 86,00 \\
Jaquinha & $13,53 \mathrm{a}$ & $63,00 \mathrm{ab}$ & 74,00 \\
\hline Médias & 13,04 & 67,31 & 73,13 \\
CV $(\%)$ & 3,64 & 14,23 & 14,74 \\
\hline Cultivar & - & $356,2292^{*}$ & $348,2500^{\mathrm{ns}}$ \\
Erro & - & 91,7292 & 116,2500 \\
\hline
\end{tabular}

Nota: ${ }^{*} \mathrm{e}^{\text {ns }}$, significativo e não significativo, respectivamente, a $5 \%$ de probabilidade pelo teste $\mathrm{F}$. Médias seguidas da mesma letra, na coluna, não diferem entre si, pelo teste de Tukey a $5 \%$ de probabilidade. Note: * and ${ }^{n s}$ significant and non-significant, respectively, at $5 \%$ probability by the $F$ test. Averages followed by the same letter, in the column, do not differ, by Tukey's test at 5\% probability.

Fonte: Autoria própria. Own authorship.

O tamanho da semente é outro componente da qualidade que vem sendo avaliado para muitas espécies. As sementes de soja classificadas em diferentes tamanhos apresentam diferenças em qualidade fisiológica. Sementes maiores (peneira 7,0 mm) apresentam maiores porcentagens de germinação e de vigor (PÁDUA et al., 2010).

As sementes da cultivar Gurgueia apresentaram maior porcentagem de plântulas normais na primeira contagem da germinação $(81,25 \%)$, expressando maior vigor em relação as sementes da cv. Guariba, entretanto, não houve diferença entre a porcentagem de germinação total das sementes das quatro cultivares (Tabela 1). Resultados semelhantes foram observados por Texeira et al. (2010), com porcentagem de germinação de 75 e 65\% para as cultivares Gurgueia e Guariba, respectivamente. Apenas a cultivar Gurgueia apresentou porcentagem de germinação acima de $80 \%$, valor esse considerado o mínimo para comercialização de sementes (MARCOS FILHO, 2015). Forti et al. (2009), observaram resultados semelhantes, onde não foram constatadas diferenças na germinação das sementes de feijão-caupi com diferentes teores de umidade. O conhecimento do vigor e da qualidade fisiológica das sementes é de suma importância, pois de acordo com Shaibu e Ibrahim (2016), um dos fatores que pode afetar a produção agrícola é a qualidade das sementes, o que influencia indiretamente a velocidade e porcentagem de emergência de plântulas e o estande final. 
Não houve efeito significativo para potencial hídrico e a interação cultivares e potenciais hídricos nos dados de emergência em areia. Observou-se efeito significativo apenas para a variável cultivar (Tabela 2). As sementes da cv. Gurgueia apresentaram valores superiores as demais com $92,5 \%$ de plântulas emergidas independente do potencial hídrico. A superioridade dessa cultivar já era esperado, pois suas sementes apresentaram maior vigor em relação as da cv. Guariba, e não houve diferença quanto ao vigor em relação às demais. Sementes mais vigorosas são mais tolerantes às condições de menor disponibilidade hídrica, favorecendo o estabelecimento da população no campo (TEKRONY; EGLI, 1991). Favorece uma emergência rápida e uniforme e o desenvolvimento de plântulas normais sob ampla variação de condições de campo (McDONALD JUNIOR, 1980).

Tabela 2. Porcentagem de plântulas normais de quatro cultivares de feijão-caupi em areia em diferentes potenciais hídricos. Percentage of normal seedlings of four cowpea cultivars in sand at different water potentials.

\begin{tabular}{|c|c|c|c|c|}
\hline \multirow{2}{*}{ Cultivares } & \multicolumn{3}{|c|}{ Potenciais hídricos (\%) } & \multirow{2}{*}{ Média } \\
\hline & 55 & 75 & 85 & \\
\hline Aracé & 83,34 & 82,50 & 90,83 & $85,56 \mathrm{~b}$ \\
\hline Guariba & 89,17 & 82,50 & 83,33 & $85,00 \mathrm{~b}$ \\
\hline Gurgueia & 94,17 & 92,50 & 90,83 & $92,50 \mathrm{a}$ \\
\hline Jaquinha & 81,67 & 89,17 & 84,17 & $85,00 \mathrm{~b}$ \\
\hline Médias & 87,09 & 86,67 & 87,29 & \\
\hline CV (\%) & & 6,50 & & \\
\hline Cultivar (C) & & $161,3426 * *$ & & \\
\hline P. Hídrico (PH) & & $1,6204^{\mathrm{ns}}$ & & \\
\hline $\mathrm{C} \times \mathrm{PC}$ & & $68,2870^{\mathrm{ns}}$ & & \\
\hline Erro & & 32,0216 & & \\
\hline
\end{tabular}

Nota: ${ }^{*} \mathrm{e}^{\text {ns }}$, significativo e não significativo, respectivamente, a $5 \%$ de probabilidade pelo teste $\mathrm{F}$. Médias seguidas da mesma letra, na coluna, não diferem entre si, pelo teste de Tukey a 5\% de probabilidade. Note: * and ${ }^{n s}$ significant and non-significant, respectively, at $5 \%$ probability by the $F$ test. Averages followed by the same letter, in the column, do not differ, by Tukey's test at 5\% probability.

Fonte: Autoria própria. Own authorship.

Observou-se que as sementes das quatro cultivares apresentaram maior emergência de plântulas em areia, independente do potencial hídrico (Tabela 2), quando comparadas com a germinação em laboratório utilizando o substrato papel germitest (Tabela 1), sendo a correlação positiva de 0,905 .

Isso é possível provavelmente devido à incidência de fungos na superfície dos tegumentos, em areia o tegumento da semente fica na superfície do substrato e dessa forma as plântulas escaparam de seus efeitos prejudiciais, não havendo a contaminação das plântulas, já no rolo de papel germitest o tegumento fica em contato direto com as plântulas, os cotilédones e o eixo embrionário contaminando-os, o que aumenta o número de plântulas infectadas e sementes mortas (FRANÇA NETO; WEST, 1985).

Houve efeito significativo para cultivares e potencial hídrico quanto ao índice de velocidade de emergência (IVE), e para a interação destes dois fatores, não houve efeito significativo (Tabela 3). O potencial hídrico da areia influenciou na velocidade de emergência 
das plântulas, independente da cultivar, o substrato com $85 \%$ da capacidade de retenção de água apresentou maior IVE (26,59), porém diferindo apenas do substrato com $55 \%$ da capacidade de retenção de água $(24,72)$. Resultados semelhante foram encontrados por Silva et al. (2013), observaram que com o aumento da disponibilidade de água houve aumento do índice de velocidade de emergência de plântulas. Segundo Ávilar et al. (2010), o estresse hídrico contribuiu para a diminuição da porcentagem de germinação de sementes e, para cada espécie, existe um valor do potencial hídrico do solo abaixo do qual a germinação não ocorre.

Tabela 3. Índice de velocidade de emergência de plântulas de sementes de quatro cultivares de feijão-caupi em areia em diferentes potenciais hídricos. Speed index of seedling emergence of four cowpea cultivars in sand in different water potentials.

\begin{tabular}{|c|c|c|c|c|}
\hline \multirow{2}{*}{ Cultivares } & \multicolumn{3}{|c|}{ Potenciais hídricos (\%) } & \multirow{2}{*}{ Média } \\
\hline & 55 & 75 & 85 & \\
\hline Aracé & 23,92 & 24,15 & 25,03 & $24,37 \mathrm{c}$ \\
\hline Guariba & 23,60 & 24,43 & 23,81 & $23,95 \mathrm{c}$ \\
\hline Gurgueia & 26,35 & 29,11 & 30,43 & $28,63 \mathrm{a}$ \\
\hline Jaquinha & 25,03 & 26,25 & 27,10 & $26,12 b$ \\
\hline Médias & $24,72 \mathrm{~B}$ & $25,99 \mathrm{AB}$ & $26,59 \mathrm{~A}$ & \\
\hline $\mathrm{CV}(\%)$ & & 5,92 & & \\
\hline Cultivar (C) & & $54,3979 * *$ & & \\
\hline P. Hídrico $(\mathrm{PH})$ & & $14,5497 * *$ & & \\
\hline $\mathrm{C} \times \mathrm{PC}$ & & $3,0891^{\mathrm{ns}}$ & & \\
\hline Erro & & 2,3235 & & \\
\hline
\end{tabular}

Nota: ${ }^{*} \mathrm{e}^{\text {ns }}$, significativo e não significativo, respectivamente, a $5 \%$ de probabilidade pelo teste $\mathrm{F}$. Médias seguidas da mesma letra, na coluna, não diferem entre si, pelo teste de Tukey a $5 \%$ de probabilidade. Note: * and ${ }^{n s}$ significant and non-significant, respectively, at 5\% probability by the $F$ test. Averages followed by the same letter, in the column, do not differ, by Tukey's test at 5\% probability.

Fonte: Autoria própria. Own authorship.

Comparando as médias das cultivares independente do potencial hídrico (Tabela 3), verificou-se que a cultivar Gurgueia se sobressaiu dentre as demais com IVE de 28,6, seguida pela Jaquinha $(26,12)$ e Aracé $(24,37)$ e Guariba $(23,95)$, não houve diferença para as duas últimas cultivares (Tabela 3). Além do vigor o tamanho das sementes também influencia o IVE, assim as sementes da cultivar Aracé apresentaram maior peso de mil sementes 308,0 g, o que pode ter contribuído por apresentar um dos menores IVE. Guerra et al., 2020 ao estudar produtividade de grãos e biomassa da parte aérea de cultivares de feijão-caupi, analisaram o peso de 1000 sementes de diferentes cultivares, encontrando valores próximos a 155 gramas. Tal resultado discrepante se justifica devido o referido trabalho ter sido realizado em campo e a cultivar aracé ter sofrido ataques severos de doenças fúngicas como o Oidio. Gomes Filho et al., 2017, ao estudar a qualidade fisiológica de sementes de feijão-caupi cultivadas no semiárido mineiro, também encontraram valores próximos a 190 gramas em 1000 sementes, resultado também justificado devido as diferenças nas condições de cultivo.

De acordo com Krzyzanowski et al. (1999), quanto menor a semente, maior a superfície de contato com a água, ocorrendo assim maior taxa de absorção de água e consequente germinação mais rápida. O maior IVE das sementes da cultivar Gurgueia (Figura 3) está 
relacionando com o vigor das mesmas, pois sementes de alto vigor apresentam maior velocidade nos processos metabólicos, propiciando emissão mais rápida da raiz primária e consequentemente menor tempo para a emergência das plântulas (MUNIZZI et al., 2010). Esses resultados podem ser correlacionados aos dados da primeira contagem do teste de germinação, cujas sementes com maior IVE apresentaram maior vigor (Tabela 2).

Dentre as cultivares de feijão-caupi avaliadas, a cultivar Gurgueia foi mais tolerante ao déficit hídrico, discordando de Araújo et al. (2018) que observaram maior tolerância ao déficit hídrico durante as fases de germinação e crescimento inicial para a cultivar BRS Guariba, quando suas sementes foram tratadas com ácido salicílico $(1 \mathrm{mM})$.

\section{CONCLUSÃO}

O déficit hídrico afeta a velocidade de germinação das sementes de feijão-caupi, porém não influencia na porcentagem de plântulas emergidas em areia, avaliadas aos 15 dias após a semeadura.

A cultivar Gurgueia apresentou maior vigor na primeira contagem de germinação e maior velocidade de germinação e porcentagem de plântulas emergidas aos 15 dias após a semeadura independente do potencial hídrico.

\section{REFERÊNCIAS BIBLIOGRÁFICAS}

ANDRADE JÚNIOR, A. S.; SANTOS, A. A.; ATHAYDE SOBRINHO, C.; BASTOS, E. A.; MELO, F. B.; VIANA, F. M. P.; FREIRE FILHO, F. R.; SILVA, J. C.; ROCHA, M. M.; CARDOSO, M. J.; SILVA, P. H. S.; RIBEIRO, V. Q. Cultivo do feijão caupi (Vigna unguiculata (L.) Walp). Teresina: Embrapa Meio-Norte, 2002. 108p. (Sistemas de Produção, 2). Disponível em: https://www.infoteca.cnptia.br. Acesso em: 02 set. 2019.

ARAÚJO, E. D.; MELO, A. S.; ROCHA, M. S.; CARNEIRO, R. F.; ROCHA, M. M. Germinação e crescimento inicial de cultivares de feijão-caupi sob estresse osmótico e ácido salicílico. Revista Caatinga, Mossoró, v. 31, n. 1, p.80-89, 2018. Disponível em: https:/www.scielo.br/scielo.php?script=sci_abstract\&pid=S1983-

$21252018000100080 \& \operatorname{lng}=$ en\&nrm=iso\&tlng=pt. Acesso em: 15 set. 2019.

ÁVILA, F. W.; BALIZA, D. P.; FAQUIN, V.; ARAUJO, J. L.; RAMOS, S. J. Interação entre silício e nitrogênio em arroz cultivado sob solução nutritiva. Revista Ciência Agronômica, Fortaleza, v. 41, n. 2, p.184-190, 2010. Disponível em: http://ccarevista.ufc.br/seer/index.php/ccarevista/article/view/470. Acesso em: 04 set. 2019.

BEZERRA, A. A. C.; AlCÂNTARA NETO, F.; NEVES, A. C.; MAGGiONI, K. Comportamento morfoagronômico de feijão caupi, cv. BRS Guariba, sob diferentes densidades de plantas. Revista Ciências Agrarias, Recife, v. 55, n. 3, p.184-189, 2012. Disponível em: https://periodicos.ufra.edu.br/index.php/ajaes/article/view/578 Acesso em: 04 set. 2019. 
BRASIL. Ministério da Agricultura, Pecuária e Abastecimento. Secretária de Defesa Agropecuária. Regras para análise de sementes. Brasília, DF: Mapa/ACS, 2009. 399 p. Disponível em: https://www.gov.br/agricultura/pt-br/assuntos/insumosagropecuarios/arquivos-publicacoes-insumos/2946_regras_analise_sementes.pdf. Acesso em: 04 set. 2019.

CARDOSO, M. J. A cultura do feijão caupi no Meio-Norte do Brasil. Teresina: Embrapa Meio-Norte, 2000. 264 p. Circular Técnico, 28. Disponível em: https://www.bdpa.cnptia.embrapa.br/consulta/busca?b=ad\&id=60604\&biblioteca=vazio\&bus ca=autoria:\%22CARDOSO,M.J.\%22\&qFacets=autoria:\%22CARDOSO,M.J.\%22\&sort=\&pa ginacao $=$ t\&paginaAtual $=1$. Acesso em: 20 set. 2019.

CARDOSO, M. J.; BASTOS, E. A.; ANDRADE JÚNIOR, A. S.; SOBRINHO, C. A. Feijão caupi: o produtor pergunta, a Embrapa responde. Brasília, DF: Embrapa, 2017. 244 p. Coleção 500 perguntas, 500 respostas. Disponível em: https://www.embrapa.br/busca-depublicacoes/-/publicacao/1077492/feijao-caupi-o-produtor-pergunta-a-embrapa-responde Acesso em: 20 set. 2019.

COMPANHIA NACIONAL DE ABASTECIMENTO - CONAB. Quarto levantamento grãos. v. 6, n. 9, 2019. 49 p. Disponível em: http://www.conab.gov.br. Acesso em: 02.07.19. Disponível em: https://www.conab.gov.br/info-agro/safras/graos/boletim-da-safra-de-graos. Acesso em: 06 set. 2019.

ENDRES, L.; SOUZA, J. L.; TEODORO, L.; MARROQUIM, P. M. G.; SANTOS, C. M.; BRITO, J. E. D. Gas exchange alteration caused by water deficit during the bean reproductive stage. Revista Brasileira de Engenharia Agrícola e Ambiental, Campina Grande, v. 14, n. 1, p.11-16, 2010. Disponível em: https://www.scielo.br/scielo.php?script=sci_arttext\&pid=S1415$43662010000100002 \&$ lang=en. Acesso em: 15 set. 2019.

FORTI, V. A.; CICERO, S. M.; PINTO, T. L. F. Efeitos de potenciais hídricos do substrato e teores de água das sementes na germinação de feijão. Revista Brasileira de Sementes, Londrina, v. $31, \quad$ n. 2, p.63-70, 2009. Disponível em: https://www.researchgate.net/publication/250037020_Efeitos_de_potenciais_hidricos_do_sub strato_e_teores_de_agua_das_sementes_na_germinacao_de_feijao. Acesso em: 04 set. 2019.

FRANÇA NETO, J. B.; WEST, S. H. Problems in evaluating viability of soybean seed infected with Phomopsis spp. Journal of Seed Technology, Europa, v. 13, n. 2, p.122-135, 1985. Disponível em: https://www.jstor.org/stable/23432988?seq=1. Acesso em: 04 set. 2019.

FROTA, K. M. G.; SOARES, R. A. M.; ARÊAS, J. A. G. Composição química do feijão caupi (Vigna unguiculata L. Walp), cultivar BRS-Milênio. Ciência e Tecnologia de Alimentos, Campinas, v. 28, n. 2, p.470-476, 2008. Disponível em: https://www.scielo.br/scielo.php?script=sci_arttext\&pid=S0101-20612008000200031. Acesso em: 06 out. 2019.

KRZYZANOWSKI, F. C.; VIEIRA, R. D.; FRANÇA NETO, J. B. Vigor de sementes: conceitos e testes. Londrina: ABRATES, 1999. 237 p. Disponível em: 
https://ainfo.cnptia.embrapa.br/digital/bitstream/item/105000/1/Vigor-de-sementes.pdf. Acesso em: 05 set. 2019.

GUERrA, A. M. N. M; EVAngelista, R. S; SAntos, E. B; Silva, M. G. M; NOUGUEIRA, W. P. Produtividade de grãos e de biomassa da parte aérea de cultivares de feijão-caupi. Revista Agrária Acadêmica, Imperatriz, v. 3, n. 3, p.40-48, 2020. Disponível em:

https://www.researchgate.net/publication/342017927_Produtividade_de_graos_e_de_biomass a_da_parte_aerea_de_cultivares_de_feijao-caupi. Acesso em: 04 set. 2019.

GOMES FILHO, J. E; ALCÂNTARA, S. F; GOMES FILHO, A.; OLIVEIRA, S. L; MOREIRA, E. F. Qualidade fisiológica de sementes de feijão-caupi cultivadas no semiárido mineiro. Revista Agrotecnologia, Goiânia, v. 8, n. 2, p.19-27, 2017. Disponível em: https://www.revista.ueg.br/index.php/agrotecnologia/article/view/5796. Acesso em: 12 set. 2019.

MAGUIRE, J. D. Speed of germination-aid in selection and evaluation for seedling emergence and vigor. Crop Science, Washington, v. 2, n. 1, p.176-177, 1962. Disponível em: https://acsess.onlinelibrary.wiley.com/doi/abs/10.2135/cropsci1962.0011183X000200020033 x. Acesso em: 11 set. 2019.

MARCOS FILHO, J. Fisiologia de sementes de plantas cultivadas. 2. ed. Londrina: ABRATES, 2015. 660p.

McDONALD JUNIOR, M. B. Vigor test subcommitte report. News Lett. Assoc. Proceeding of Association of Official Seed Analysts, v. 54, n. 1, p.37-40, 1980.

MENDES, R. M. S.; TÁVORA, F. J. A. F.; PINHO, J. L. N.; PITOMBEIRA, J. B. Relações fonte-dreno em feijão-de-corda submetido à deficiência hídrica. Ciência Agronômica, Fortaleza, v. 38, n. 1, p.95-103, 2007. Disponível em: http://ccarevista.ufc.br/seer/index.php/ccarevista/article/view/158. Acesso em: 11 set. 2019.

MUNIZZI, A.; BRACCINI, A. L.; RANGEL, M. A. S.; SCAPIM, C. A.; ALBRECHT, L. P. Qualidade de sementes de quatro cultivares de soja, colhidas em dois locais no estado de Mato Grosso do Sul. Revista Brasileira de Sementes, Londrina, v. 32, n. 1, p.176-185, 2010. Disponível em: https://www.scielo.br/scielo.php?pid=S010131222010000100020\&script=sci_abstract\&tlng=pt. Acesso em: 04 set. 2019.

OLIVEIRA, A. D.; FERNANDES, E. J.; RODRIGUES, T. J. D. Condutância estomática como indicador de estresse hídrico em Feijão. Engenharia Agrícola, Jaboticabal, v. 25, n. 1, p.86-95, 2005. Disponível em: https://www.researchgate.net/publication/250982880_Condutancia_estomatica_como_indicad or_de_estresse_hidrico_em_feijao. Acesso em: 04 set. 2019.

PÁDUA, G. P.; ZITO, R.K.; ARANTES, N. E.; FRANÇA NETO, J. B. Influência do tamanho da semente na qualidade fisiológica e na produtividade da cultura da soja. Revista Brasileira de Sementes, Londrina, v. 32, n. 3, p.9-16, 2010. Disponível em: https://www.scielo.br/scielo.php?script=sci_arttext\&pid=S0101-31222010000300001. Acesso em: 06 out. 2019. 
ROCHA, M. M.; SILVA, K. J. D.; MENEZES JUNIOR, J. A. N. Sistema de produção Embrapa: Cultivo de feijão caupi. Teresina: Embrapa Meio-Norte, 2017. 93 p. Disponível em: https://www.spo.cnptia.embrapa.br/conteudo?p_p_id=conteudoportlet_WAR_sistemasdeprod ucaolf6_1galceportlet\&p_p_lifecycle $=0 \& p \_p \_s t a t e=$ normal $\& p \_p \_$mode $=v i e w \& p \_p \_c o l i d=$ column-2\&p_p_col_count=1\&p_r_p_-76293187_sistemaProducaold=9109\&p_r_p_996514994_topicoId=10505. Acesso em: 04 set. 2019.

SHAIBU, A. S.; IBRAHIM, S. I. Genetic variability and heritability of seedling vigour in common beans (Phaseolus vulgaris L.) in Sudan Savana. Jornal Internacional de Política e Pesquisa Agrícola, Kano, v. 4, n. 4, p.62-66, 2016.

SILVA, A. J.; UCHÔA, S. C. P.; ALVES, J. M. A.; LIMA, A. C. S.; SANTOS, C. S. V.; OLIVEIRA, J. M. F.; MELO, V. F. Resposta do feijão-caupi à doses e formas de aplicação de fósforo em Latossolo Amarelo do Estado de Roraima. Acta Amazônica, Manaus, v. 40, n. 1, p.31-36, 2010. Disponível em: https://www.scielo.br/scielo.php?pid=S004459672010000100004\&script=sci_abstract\&tlng=pt. Acesso em: 04 set. 2019.

SILVA, F. A. S. ASSISTAT - Sistema para análise estatística. Versão 7.7. Campina Grande: DEAG-CTRN-UFCG, 2013. Disponível em: https://assistat.software.informer.com/. Acesso em: 04 set. 2019.

SOUSA, C. C. M.; PEDROSA, E. M. R.; ROLIM, M. M.; OLIVEIRA FILHO, R. A.; SOUSA, M. A. L. M.; PEREIRA FILHO, J. V. Crescimento e respostas enzimáticas do feijoeiro caupi sob estresse hídrico e nematoide de galhas. Revista Brasileira de Engenharia Agrícola e Ambiental, Campina Grande, v. 19, n. 2, p.113-118, 2015. Disponível em: https://www.scielo.br/scielo.php?script=sci_arttext\&pid=S1415-43662015000200113. Acesso em: 04 set. 2019.

TEIXEIRA, I. R.; SILVA, G. C.; OLIVEIRA, J. P. R.; SILVA, A. G.; PELÁ, A. Desempenho agronômico e qualidade de sementes de cultivares de feijão-caupi na região do cerrado. Revista Ciência Agronômica, Fortaleza, v. 41, n. 2, p.300-307, 2010. Disponível em: http://ccarevista.ufc.br/seer/index.php/ccarevista/article/view/747. Acesso em: 04 out. 2019.

TEKRONY, D. M.; EGLI, D. B. Relationship of seed vigor to crop yield: a review. Crop Science, Europa, v. 31, n. 3, p.816-822, 1991.

YOKOYAMA, L. P. Tendências de mercado e alternativas de comercialização do feijão. Santo Antônio de Goiás: Embrapa Arroz e Feijão, 2002. 4p. Disponível em: https://www.embrapa.br/busca-de-publicacoes/-/publicacao/210625/tendencias-de-mercado-ealternativas-de-comercializacao-do-feijao. Acesso em: 06 out. 2019. 